\title{
Coronavirus outbreaks: prevention and management recommendations
}

\author{
Zakir Khan $^{1,2} \cdot$ Khayal Muhammad $^{3} \cdot$ Ali Ahmed $^{4} \cdot$ Hazir Rahman $^{5}$
}

Published online: 7 March 2020

(c) Springer Nature Switzerland AG 2020

\section{Introduction}

In December 2019, Wuhan, Hubei province, China, became the center of an outbreak of pneumonia of unknown cause, which raised intense attention not only within China but also internationally. By the 7 th of January 2020, Chinese scientists had isolated a novel coronavirus from infected patients in Wuhan.

This strain of coronavirus became officially known as the severe acute respiratory syndrome coronavirus 2 (SARSCoV-2), and also referred to as 2019-nCoV. The infection caused by this virus is known as coronavirus disease-2019 (COVID-19) [1]. 2019-nCoV is a beta-coronavirus, as are the viruses that cause severe acute respiratory syndrome (SARS) and Middle East respiratory syndrome (MERS) $[1,2]$. These viruses are zoonotic (i.e. transmitted between animals and humans) and have their origins in bats. Most people become infected with these viruses at some point in their lives, and usually the duration of illness is short.

Khayal Muhammad

khayal866@gmail.com

Zakir Khan

zakirkhan300@gmail.com

Ali Ahmed

ali.ahmed@monash.edu

Hazir Rahman

hazirrahman@awkum.edu.pk

1 Department of Pharmacology (Pharmacovigilance), Institute of Health Sciences, Cukurova University, Adana, Turkey

2 Department of Pharmacy, Quaid-i-Azam University, Islamabad, Pakistan

3 Department of Pharmacy, Comsat University (Abbottabad Campus), Abbottabad, Pakistan

4 School of Pharmacy, Monash University, Subang Jaya, Selangor, Malaysia

5 Department of Microbiology, Abdul Wali Khan University Mardan (AWKUM), Mardan, Pakistan
However, a comprehensive clinical picture of COVID-19 is still not entirely clear [2].

Cases of COVID-19 are no longer limited to Wuhan, with the increasing number of cases and widening geographical spread raising grave concerns about the future trajectory of the outbreak. Consequently, the COVID-19 epidemic has led to the implementation of extraordinary public health measures to reduce further spread of the virus within China and elsewhere [3, 4].

\section{Spread of COVID-19}

According to the World Health Organization (WHO) situation report of the 13th of February 2020, data on the COVID-19 outbreak are as follows:

- 46,997 cases confirmed globally with 6484 cases classified as 'severe'.

- Almost all $(46,550)$ of these confirmed cases were in mainland China, with 1368 deaths.

- 4127 patients fully recovered.

- 447 confirmed cases outside China with one death.

By the middle of February 2020, cases of COVID-19 had been reported in the Western Pacific region (Singapore, Japan, Republic of Korea, Malaysia, Viet Nam, Australia, Philippines, Cambodia), South-East Asia (Thailand, India, Nepal, Sri Lanka), North America (the USA and Canada), Europe (Russian Federation, Spain, Belgium, Finland, Sweden, Germany, France, UK and Italy) and the Eastern Mediterranean region (United Arab Emirates) [4].

Due to the increased transmission of 2019-nCoV, the WHO has conducted risk assessments, which have concluded that China is at "very high" risk, while the threat of the virus has been established as a "high" risk at the regional and global level $[5,6]$. 


\section{Transmission and symptoms}

COVID-19 is spread due to close person-to-person contact via coughing or sneezing, similar to the transmission of influenza and other respiratory pathogens [1]. People with cardio-pulmonary complaints, weakened immune systems, infants and older adults are more prone to COVID-19.

Symptoms of COVID-19 include sneezing, cough, sore throat, fever, headache and feeling of being unwell $[3,7]$, which may appear in a few as 2 days, or as long as 14 days, after exposure to the virus [3, 7]. Lower-respiratory tract ailments, such as pneumonia or bronchitis, may sometimes be caused by human coronaviruses. COVID-19 symptoms are often mild, with $\approx 20 \%$ of infections progressing to severe diseases, such as pneumonia, respiratory failure and, in some cases, death [8].

\section{Management of COVID-19}

According to the US Centers for Disease Control and Prevention (CDC), there is no specific recommended antiviral therapy for COVID-19. Individuals with COVID-19 require palliative care to help relieve symptoms, and those with severe disease may require care to support vital organ functions [9]. Intravenous drips can be used to maintain blood pressure, fluids given to manage diarrhoea and ibuprofen provided for pain relief in mild cases [10].

Active surveillance for new cases and close monitoring of their contacts are necessary to control the spread of COVID-19. To improve detection efficiency, front-line clinics, apart from local centers for disease control and prevention, should be armed with validated point-of-care diagnostic kits. Education campaigns should be launched to promote precautions for travelers, including frequent hand-washing, cough etiquette, and use of personal protection equipment (e.g. masks) when visiting public places. Also, the general public should be motivated to report fever and other risk factors for viral infection, including travel history to affected area and close contacts with confirmed or suspected cases [11, 12].

\section{CDC and WHO recommendations}

COVID-19 is a global public health threat. Understanding the characteristics of the virus, its mode of transmission, the severity of illness and available medical or other measures are crucial for the control of this viral disease. The $\mathrm{CDC}$ is closely monitoring this situation and is working with the WHO and state and local public health partners to respond to this emerging public health risk $[12,13]$.

The WHO has developed standard recommendations for the reduction of exposure and transmission of a range of infections [14]. These recommendations include: regular cleaning of hands; covering the mouth and nose with tissue while coughing and sneezing, then immediately throwing the tissue away and washing hands; avoiding close contact with infected persons; seeking medical care in case of fever and cough; sharing past travel history with healthcare providers; avoiding direct unprotected contact with live animals and surfaces in areas with current reported cases of novel coronavirus infections; avoiding the consumption of raw or undercooked animal products; and handling raw meat, milk or animal organs with care to prevent cross-contamination [15]. According to currently available information regarding COVID-19, the WHO advises that essential precautions and actions should be implemented to minimize the risk of exportation or importation of the disease [16].

\section{What role can pharmacists play?}

The International Pharmaceutical Federation is emphasizing the active role of community and hospital pharmacists can play in preventing the spread of COVID-19 [17]. Pharmacists are often a reliable and first point of contact for individuals having concerns or needing information and advice regarding ailments. Moreover, pharmacists are readily available at community pharmacies and hospital and accessible to the general population.

Essential responsibilities of pharmacists include: having appropriate medicinal products in stock; promoting proper handwashing to prevent disease; controlling in-hospital infection; and providing patient care and support. Pharmacists also play a crucial role in the prevention, early detection of certain types of new cases and referring suspected cases to the relevant healthcare authorities [17].

General recommendations on managing COVID-19 are modified regularly to mirror findings from large clinical trials, cohort studies, and emerging research data. Pharmacists should be familiar with the existing standards of treatment for viral infections, in order to provide individuals diagnosed with COVID-19 will appropriate management and treatment. Pharmacists should also be familiar with prevention and treatment protocols for opportunistic infections that arise in combination with COVID-19. 


\section{Take home messages}

- Keep up-to-date with information/recommendations from the WHO, CDC and other organizations about COVID19 , a new, rapidly spreading and potentially serious coronavirus infection of global concern.

- Take measures to prevent the transmission, and thereby the spread, of this virus.

- Focus treatment on relieving the symptoms and preventing serious outcomes, as there is no specific antiviral therapy.

- Be aware that pharmacists have a crucial role in proactively providing other healthcare professionals and the public with information and recommendations for preventing, detecting, treating, managing and controlling coronavirus infections.

- Encourage collaboration between healthcare professionals to detect and refer new suspected cases of COVID19 to the relevant healthcare authorities, as well as to improve patient care and safety.

Author contributions $\mathrm{ZK}$ and $\mathrm{KM}$ were involved in the concept, design and data collection of the study. AA and HR carried out the critical evaluation and interpretation of the data. ZK wrote the first draft of the manuscript, and all authors contributed to subsequent drafts. All authors revised the manuscript and approved the final version for submission.

\section{Compliance with ethical standards}

Funding No funding was received for the preparation or publication of this article.

Conflict of interest The authors declare no relevant conflicts of interest.

\section{References}

1. World Health Organization. Coronavirus. Available from: https:// www.who.int/health-topics/coronavirus. Accessed 13 Feb 2020.

2. Centers for Disease Control and Prevention. Severe acute respiratory syndrome. Available from: https://www.cdc.gov/sars/index .html. Accessed 13 Feb 2020.

3. Centers for Disease Control and Prevention. Coronavirus symptoms and diagnosis. Available from: https://www.cdc.gov/coron avirus/about/symptoms.html. Accessed 15 Feb 2020.

4. World Health Organization. Coronavirus disease 2019 (COVID19) situation report: 24 . Available from: https://www.who.int/ docs/default-source/coronaviruse/situation-reports/20200213-sitre p-24-covid-19.pdf. Accessed 14 Feb 2020.

5. Wang C, Horby PW, Hayden FG, et al. A novel coronavirus outbreak of global health concern. Lancet. 2020;395(10223):470-3.

6. World Health Organization. Novel coronavirus (2019-nCoV) situation report:21. Available from:https://www.who.int/docs/defau 1t-source/coronaviruse/situation-reports/20200210-sitrep-21-ncov. pdf?sfvrsn=947679ef_2. Accessed 14 Feb 2020.

7. John Hopkins University. 2019-nCoV global cases by John Hopkins CSSE. Available from: https://gisanddata.maps.arcgis.com/ apps/opsdashboard/index.html\#/bda7594740fd40299423467b4 8e9ecf6. Accessed 15 Feb 2020.

8. World Health Organization). Coronavirus disease (COVID-19) outbreak. Available from: https://www.who.int/emergencies/disea ses/novel-coronavirus-2019. Accessed 15 Feb 2020.

9. World Health Organization. Novel coronavirus (2019-nCoV) situation report: 8. Available from: https://www.who.int/docs/defau 1t-source/coronaviruse/situation-reports/20200128-sitrep-8-ncovcleared.pdf?sfvrsn=8b671ce5_2. Accessed 15 Feb 2020.

10. Centers for Disease Control and Prevention. Prevention, treatment of novel coronavirus (2019-nCoV). Available from: https://www. cdc.gov/coronavirus/2019-ncov/about/prevention-treatment.html. Date accessed: 16 Feb 2020.

11. BBC News. How are coronavirus patients treated? Available from: https://www.bbc.com/news/world-asia-china-51295415. Accessed 16 Feb 2020.

12. Patel A, Jernigan DB. Initial public health response and interim clinical guidance for the 2019 novel coronavirus outbreak: United States. Available from: https://www.cdc.gov/mmwr/volumes/69/ wr/mm6905e1.htm. Accessed 14 Feb 2020.

13. Centers for Disease Control and Prevention. Novel coronavirus 2019 situation summary, Wuhan, China. Available from: https:// www.cdc.gov/coronavirus/2019-nCoV/summary.html. Accessed 16 Feb 2020.

14. World Health Organization. Statement on the second meeting of the International Health Regulations (2005) Emergency Committee regarding the outbreak of novel coronavirus (2019-nCoV). Available from: https://www.who.int/news-room/detail/30-012020-statement-on-the-second-meeting-of-the-international-healt h-regulations-(2005)-emergency-committee-regarding-the-outbr eak-of-novel-coronavirus-(2019-ncov). Accessed 16 Feb 2020.

15. World Health Organization. Novel coronavirus (2019-nCoV) advice for the public. Available from: https://www.who.int/ emergencies/diseases/novel-coronavirus-2019/advice-for-publi c. Accessed 17 Feb 2020.

16. World Health Organization. Updated WHO advice for international traffic in relation to the outbreak of the novel coronavirus 2019-nCoV. Available from: https://www.who.int/ith/202027-01-outbreak-of-Pneumonia-caused-by-new-coronavirus/en/. Accessed 13 Feb 2020.

17. The International Pharmaceutical Federation (FIP). Coronavirus 2019-nCoV outbreak: Information and interim guidelines for pharmacists and the pharmacy workforce. Available from: https ://www.fip.org/file/4413. Accessed 17 Feb 2020. 